refinement) was then used for molecular replacement calculations against the P1 dataset. Three solutions were found, related by a local three-fold axis approximately aligned with the body-diagonal of the unit cell, producing a correlation coefficient of 0.42 (the next highest solution being 0.28 ). Electron density for parts of the complex missing from the starting model coordinates, including some residues at the $\mathrm{C}$ terminus and in the $\mathrm{F}-\mathrm{G}$ loop of p50rhoGAP, were readily interpretable. Electron density maps were 3 -fold averaged using the program $\mathrm{DM}^{27}$. The subset of reflections flagged for omission from the refinement process were also omitted from DM phase refinement. Manual model adjustment was carried out using the $\mathrm{O} \operatorname{program}^{28}$; reciprocal space refinement was done with REFMAC ${ }^{27}$ using DM-modified phases as additional restraints. Non-crystallographic positional and thermal restraints were applied in PROTIN/REFMAC, with tight targets for both main and side-chains. Water molecules were built into peaks greater than $3.5 \sigma$ in averaged difference electron density maps using the program $\mathrm{ARP}^{27}$ and retained only if they met strict $B$-factor (less than 1.5 greater than average for protein) and stereochemical requirements.

Received 25 April; accepted 25 June 1997.

1. Bourne, H. R., Sanders, D. A. \& McCormick, F. The GTPase superfamily: a conserved switch for diverse cell functions. Nature 348, 125-132 (1990).

2. Bourne, H. R., Sanders, D. A. \& McCormick, F. The GTPase superfamily: conserved structure and molecular mechanism. Nature 349, 117-127 (1991).

3. Paterson, H. F. et al. Microinjection of recombinant $\mathrm{p} 21$ rho induces rapid changes in cell morphology. J. Cell. Biol. 111, 1001-1007 (1990).

4. Hall, A. The cellular functions of small GTP-binding proteins. Science 249, 635-640 (1990).

5. Ridley, A. J. \& Hall, A. The small GTP-binding protein rho regulates the assembly of focal adhesions and actin stress fibers in response to growth factors. Cell 70, 389-399 (1992).

6. Qiu, R.-G., Chen, J., Kirn, D., McCormick, F. \& Symns, M. An essential role for Rac in Ras transformation. Nature 374, 457-459 (1995).

7. Ridley, A. J. Rho: theme and variations. Curr. Biol. 6, 1256-1264 (1996)

8. Coso, O. A. et al. The small GTP-binding proteins Racl and Cdc42 regulate the activity of the JNK/ SAPK signaling pathway. Cell 81, 1137-1146 (1995).

9. Minden, A., Lin, A., Claret, F.-X., Abo, A. \& Karin, M. Selective activation of the JNK signaling cascade and c-Jun transcriptinal activity by the small GTPases Rac and Cdc42Hs. Cell 81, 1147-1157 (1995).

10. Lancaster, C. A. et al. Characterization of rhoGAP. J. Biol. Chem. 269, 1137-1142 (1994).

11. Lamarche, N. \& Hall, A. GAPs for rho-related GTPases. Trends Genet. 10, 436-440 (1994).

12. Coleman, D. E. et al. Structures of active conformations of $\mathrm{G}_{\mathrm{i \alpha l}}$ and the mechanism of GTP hydrolysis. Science 265, 1405-1412 (1994).

13. Pai, E. F. et al. Refined crystal structure of the triphosphate conformation of H-ras p21 at 1.35A resolution: implications for the mechanism of GTP hydrolysis. EMBO J. 9, 2351-2359 (1990).

14. Schlichting, I. et al. Time-resolved X-ray crystallographic study of the conformational change in HaRas p21 protein on GTP hydrolysis. Nature 345, 309-315 (1990).

15. Prive, G. G. et al. X-ray crystal structures of transforming p21 ras mutants suggest a transition-state stabilization mechanism for GTP hydrolysis. Proc. Natl Acad. Sci. USA 89, 3649-3653 (1992).

16. Hirshberg, M., Stockley, R. W., Dodson, G. \& Webb, M. R. The crystal structure of human racl, a member of the rho-family complexed with a GTP analogue. Nature Struct. Biol. 4, 147-152 (1997).

17. Scheffzek, K., Lautwein, A., Kabsch, W., Ahmadian, M. R. \& Wittinghofer, A. Crystal structure of the GTPase-activating domain of human p120GAP and implications for the interaction with Ras. Nature 384, 591-596 (1996)

18. Barrett, T. et al. The structure of the GTPase-activating domain from p50rhoGAP. Nature 385, 458 461 (1997).

19. Noel, J. P., Hamm, H. E. \& Sigler, P. B. The $2.2 \AA$ crystal structure of transducin- $\alpha$ complexed with GTP- $\gamma$ S. Nature 366, 654-663 (1993)

20. Sondek, J., Lambright, D. G., Noel, J. P., Hamm, H. E. \& Sigler, P. B. GTPase mechanism of G-protein from the $1.7 \AA$ crystal structure of transducin $\alpha \cdot G D P ~ A l F 44_{4}^{-}$. Nature 372, 276-279 (1994).

21. Tesmer, J. J. G., Berman, D. M., Gilman, A. G. \& Sprang, S. R. Structure of RGS4 bound to AlF4activated $\mathrm{G}_{\mathrm{i} \alpha}$ : Stabilization of the transition state for GTP hydrolysis. Cell 89, 251-261 (1997).

22. Milburn, M. V. et al. Molecular switch for signal transduction: Structural differences between active and inactive forms of protooncogenic ras proteins. Science 247, 939-945 (1990).

23. Goody, R. S. et al. Studies on the structure and mechanism of H-ras p21. Phil. Trans. R. Soc. Lond. B 336, 3-11 (1992)

24. Mittal, R., Ahmadian, M. R., Goody, R. S. \& Wittinghofer, A. Formation of a transition-state analog of Ras GTPase reaction by Ras GDP, tetrafluoroaluminate, and GTPase-activating proteins. Science 273, 115-117 (1996)

25. Smith, D. B. \& Johnson, K. S. Single-step purification of polypeptides expressed in Escherichia coli as fusions with glutathione S-transferase. Gene 67, 31-40 (1988).

26. Otwinowski, Z. \& Minor, W. Data Collection and Processing (eds Sawyer, L., Isaacs, N. \& Bailey, S.) 556-562 (SERC Daresbury Laboratory, Warrington, 1993).

27. CCP4 The CCP4 suite: programs for protein crystallography Acta Crystallogr. D 50, 760-763 (1994).

28. Jones, T. A., Zhou, J. Y., Cowan, S. W. \& Kjeldgaard, M. Improved methods for building protein models in electron density maps and the location of errors in these models. Acta Crystallogr. A 47, $110-119$ (1991).

29. Kraulis, P. J. MOLSCRIPT: a program to produce both detailed and schematic plots of protein structures. J. Appl. Crystallogr. 24, 946-950 (1991).

Acknowledgements. We thank M. Hirshberg for making coordinates of Racl available before general release, E. Skordalakes for assistance with data collection, A. Hall for the gift of rhoA and rhoGAP expression systems, E. Manser and L. Lim for construction and characterization of the Cdc $42 \mathrm{Hs} \Delta 7$ expression system, G. Dodson and D. Trentham for critical reading of this manuscript, and A. Savoia (Trieste) and A. Thompson (ESRF) for beamline assistance. D.O. and E.L. Thank the European commission for financial support and the BBSRC and Welcome Trust for support to the Cambridge Centre for Molecular Recognition. K.R. is funded by an EEC TMR fellowship.

Correspondence and requests for materials should be addressed to S.J.G. (e-mail: s-gambli@anika.nimr. mrc.ac.uk). Coordinates have been deposited with the Brookhaven DataBank under accession number 1AM4. corrections

\section{A new chromosomal protein essential for mitotic spindle assembly}

\section{Jing-Ping Yeo, Frank Alderuccio \& Ban-Hock Toh}

Nature 367, 288-291 (1994)

In this Letter, we identified a chromosomal antigen and its corresponding cDNA by using a human autoimmune serum. We named this $47 \mathrm{~K}$ autoantigen RMSA1 (for regulator of mitotic spindle assembly 1). Tugendreich et al. ${ }^{1}$ and Margalit et al. ${ }^{2}$ observed that the open reading frame (ORF) we ascribed to the cDNA of RMSA1 contains two Alu repeat sequences. Although truncated Alu repeats have been identified in the ORFs of messenger RNAs, Tugendreich et al. suggested that our reported cDNA may be an expressed pseudogene or a cloning artefact. We have now repeated the experiments (but without J.-P.Y., who has left our laboratory) and find that the reported RMSA cDNA is indeed a cloning artefact and that the identity of the chromosomal protein, which we have confirmed reacts by immunofluorescence with the autoimmune serum, remains unknown.

1. Tugendreich, S. et al. Nature 370, 106 (1994).
2. Margalit, H., Nadir, E. \& Ben-Sasson, S. A. Cell 78, 173-174 (1994).

\section{RNA recognition and translational regulation by a homeodomain protein}

\section{Josh Dubnau \& Gary Struhl}

Nature 379, 694-699 (1996)

In this Article, we presented genetic and biochemical evidence that Bicoid (Bcd) protein binds and regulates the translation of caudal (cad) messenger RNA through direct interactions between the Bcd homeodomain and a discrete target sequence in the $3^{\prime}$ UTR of cad mRNA, the Bcd response element (BRE). Although our main findings have been verified by additional experiments (see page 634 in this issue $)^{1}$, we cannot reproduce a subset of the results under the conditions initially reported.

The results we cannot repeat are: (1) the ultraviolet crosslinking and band-shift experiments which provided evidence for sequencespecific interactions between the Bcd homeodomain and the BRE (Figs 4c and 5); and (2) a bicistronic transcript experiment (Fig. 6) which provided evidence that the BRE mediates Bcd-dependent regulation of $\mathrm{Cad}$ at the level of translational initiation. However, biochemical evidence that the Bcd homeodomain can bind the BRE in a sequence-specific fashion has now been obtained in independent experiments using different binding conditions ${ }^{1}$. In addition, we have successfully repeated the key genetic experiments indicating that $\mathrm{Bcd}$ regulates Cad expression in a way that depends on both the Bcd homeodomain and the cad BRE (see Figs 1, 2c i, v and vi, 2d vi $\left(\mathrm{bcd}^{+}, \mathrm{bcd} \mathrm{d}^{\mathrm{El}}\right)$, and 3 of our Article).

These errors do not alter our main interpretation that the homeodomain of Bcd mediates RNA recognition and translational regulation by the intact protein, but we apologize for any confusion they may have caused.

1. Chan, S.-K. \& Struhl, G. Sequence-specific RNA binding by Bicoid. Nature 388, 634 (1997). 